\title{
Intelligent System for the use of the Scientific Research Information System
}

\author{
Khaoula Benmoussa, Majida Laaziri, Samira Khoulji \\ Information System Engineering Research Group \\ National School of Applied Sciences \\ Abdelmalek Essaadi University \\ Tetouan, Morocco
}

\author{
Mohamed Larbi Kerkeb \\ Information System Engineering Research Group \\ Faculty of Sciences \\ Abdelmalek Essaadi University \\ Tetouan, Morocco
}

\begin{abstract}
As part of the digital governance of scientific research of Moroccan universities and national research institutions, the Ministry of Higher Education, Scientific Research and Executive Training has shown great interest in setting up the Moroccan Information System for Scientific Research (SIMARECH). Despite a great effort that was made for the implementation of SIMARECH in Moroccan universities, difficulties appear in the use of this information system. This prompted Abdelmalek Essaadi University to consider developing an intelligent system to provide remote training for users to use SIMARECH to facilitate the learning process, reduce administrative costs for displacement to national universities and save time training, etc. This article is in the context of a new rapidly expanding learning paradigm in the field of artificial intelligence for education. It encompasses the design and development of a SIMARECH Intelligent Learning System of Global Use and Features to provide customized learning and adapt to different environments as well as the types of learning scenarios for user training of SIMARECH, this system is named ISSIMA (intelligent system for the use of SIMARECH).
\end{abstract}

Keywords-Moroccan Information System for Scientific Research (SIMARECH); intelligent system; E-learning systems; learning process; interactive learning environments; intelligent tutoring systems

\section{INTRODUCTION}

The academic world is full of enormous potentialities and skills, unfortunately still hidden. Universities are facing change and ICTs are at the heart of this ongoing process. These technologies reconfigure the teaching environment by introducing "forms of innovation". ICTs make it possible to enrich pedagogical content, to stimulate interactions between learners and between learners and teachers, to further individualize the training and reach populations previously excluded from university training; hence, the challenges that have been set by Moroccan universities, particularly in the field of scientific research.

The 2013-2016 action plan [1] has devoted an axis to the promotion of scientific, technical and innovation research, which is based on several projects, among them we find the development of a computer system for scientific research in universities. Indeed, a Moroccan information system for scientific research (SIMARECH) is set up by Abdelmalek Essaadi University and generalized to the various universities after having tested it at this university [2]. This system tracks research activities at the national level and the information needed to manage research. In order for the Abdelmalek Essaadi University to ensure the application, integration and efficient and effective use of the latter by the users at the various national universities, the idea of developing an intelligent system appeared.

This intelligent system named ISSIMA will be devoted to train teacher-researchers, those who are responsible of structures, deans, and administrative staff of universities. In order to facilitate the use of SIMARECH, reduce administrative costs (mainly due to displacement and commitment of trainers, booking rooms and materials, etc.) also save training time (meetings, telephone exchanges, etc.) and avoid the problem of the availability of SIMARECH users in a specific time.

The approaches implemented for the design and development of ISSIMA are derived from both knowledge engineering and software engineering methods. Abdelmalek Essaadi University has taken great care in the study and the choice of the methods used, according to the field and the objectives of the training, to guarantee as result a robust and technically and scientifically valid system.

\section{CROSS-BORDER DigitAl SERVICES FROM ABDELMALEK ESSAADI UNIVERSITY}

The experience and lessons learned from the Ministry's emergency program, the desire for consolidation of autonomy of Moroccan universities as well as the new instruments made available to respond effectively to the expectations of stakeholders (Students, Companies, Public Authorities) lead to the definition of a new approach to university governance (modernizing its governance and structures). both in its organization and in the field of its competences inevitably going through the modernization of its information system [3].

In the context of autonomy and international, the proliferation of digital services (intranet, e-mail, forums, website publication, online courses, online document collections, e-administration, etc.) has experienced an unprecedented boom in the history of the Moroccan university. Corollary to this massive deployment of ICT, new issues are now posed with insistence: problems relating to functional consistency, more others are technical relating to the interoperability between applications, others finally relating to the cultural and organizational aspect [4]. 
Defying these difficulties, technological evolution and feasibility helping, Tempus projects and emergency program supporting, Abdelmalek Essaadi university (UAE) set itself the objective [4], [5], to adapt its organization and equip itself with the tools and methods to carry out its missions and meet the challenges it has set itself. Adapt Its Information System Department has entrusted, missions of design, evolution and urbanization of the information system (business applications and digital services); integration, studies and development of digital applications and services, and administration and maintenance of the information system [6].

This is how the UAE moved to digital governance by taking several actions, complementary and of equal importance, namely [3], [6]:

- The implementation of an original information system dedicated to scientific research, "SIRech", renamed today "SIMARECH" following its adoption by all Moroccan universities.

- The implementation of a management information system for university cooperation SIMACoop.

- The implementation of an integrative single access system for all digital services at the university: a Digital Work Environment (ENT).

- The implementation of an integration portal dedicated to the winners of the university and companies called "KHIRIJ".

- Development of the Information and Management System (GIS).

- Involvement in the information system "JAMIATI".

It goes without saying that the UAE continues, beyond its priorities, to devote efforts and resources to other important missions in the continuity of previous projects. This is particularly the international influence of the university; its ambition in this area is to focus on the international research component by strengthening exchanges and scientific collaborations with EU countries and Latin American countries. aware that the trend has already begun with results showing that research in the UAE is oriented internationally with $82 \%$ of the indexed publications made in the context of cooperation [6], [7].

\section{MOROCCAN INFORMATION SYSTEM FOR SCIENTIFIC RESEARCH (SIMARECH)}

In the context of the mobilization of all the actors around the emergency program of the Moroccan Ministry of Higher Education, and in the spirit of careful planning of the strategies of the valorization of the research, that the University Abdelmalek Essaadi presents the platform SIMARECH. It is not only a tool for steering research in universities, but also in its institutions and structures, with the ultimate aim of supporting researchers and enhancing their scientific output.

SIMARECH is indeed the result of a collaborative work, its creation was at the Abdelmalek Essaadi University in 2008 [2]. The first version was in fair testing phase at the UAE institutions. Later, other Moroccan universities and national research institutions were gradually included in the implementation of other versions of SIMARECH in order to offer new features that meet the expectations and needs expressed by users.

SIMARECH is an IT platform that facilitates the collection and management of data on research activities and results within an organization [2]. It aims to present in a coherent way the establishments, the research units within the university, including the personnel and their scientific activities (publications, patents, events, equipment, etc.), as well as the follow-up of the financial means and the international activities (partnership agreements, congresses, etc.). Researchers, administrators, and evaluators have all the tools they need to monitor research results, improve visibility, and efficiently allocate available resources (Fig. 1).

Initially, the system was structured to present and include a range of information services (programs, projects, events and products resulting from the activities of the research developed, etc.) for the use of users (teacher-researchers, those who are responsible for structures, deans, and administrative staff) according to their role (Fig. 2). Moreover, at the strategic level, it aims to have a set of indicators and available research statistics. Modular nature of the system and flexibility of its data model allowing different users to access certain information and functionalities throughout the process, and facilitate the processing, organization and transmission of information in accordance with international standards [2], [8].

SIMARECH is developed in stages with incremental improvements to the usability of the tool for users. The UAE team has involved users from beginning to end, in order to i) be familiar with the information system, ii) have a vision of what the SI is aiming for and therefore want to provide data to achieve this, and iii) that their wishes regarding what the IS could do are reflected in its design. This avoids that there are major differences between the expected SI and that which is realized.

Ensuring the proper use of SIMARECH system has always been a real concern of the UAE within Moroccan universities and national research institutions. A huge investment is already being made to provide necessary training for the implementation of SIMARECH by displacement and organizing meetings, personal visits or telephone and e-mail exchanges, etc. to help users of SIMARECH (the teacherresearchers, those who are responsible for structures, deans and administrative staff) to understand the features and use of the system. But despite all the efforts made by UAE and that SIMARECH integrates an intuitive and usability interface for users to adapt with the system, difficulties and problems arise (especially teachers who are not used to using a such a system, faculty of humanities and human sciences, the elderly, etc.) to use and access the various features of the system.

A solution to be effective should be able to adapt to the user by providing effective learning tools, and at the same time reduce administrative costs and save training time. Indeed, each individual according to his abilities has his own strategies and pace of learning. For this, the university has thought to develop an intelligent system to meet this need. Intelligent tutoring system (ITS) are ideal solutions in these conditions 
because they are equipped with environments that provide individualized, adaptive and quality learning [9].

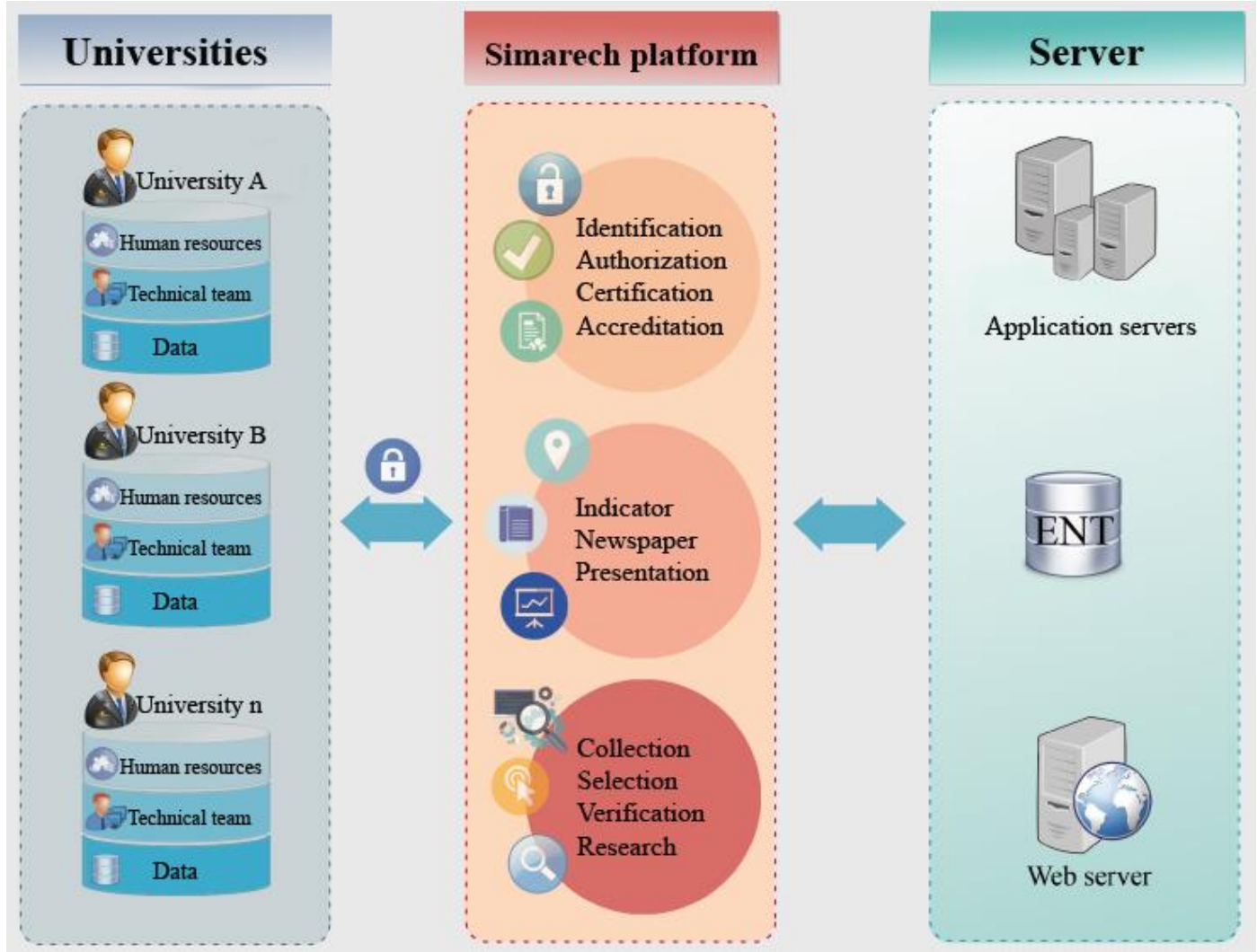

Fig. 1. Integration of SIMARECH in universities [2].

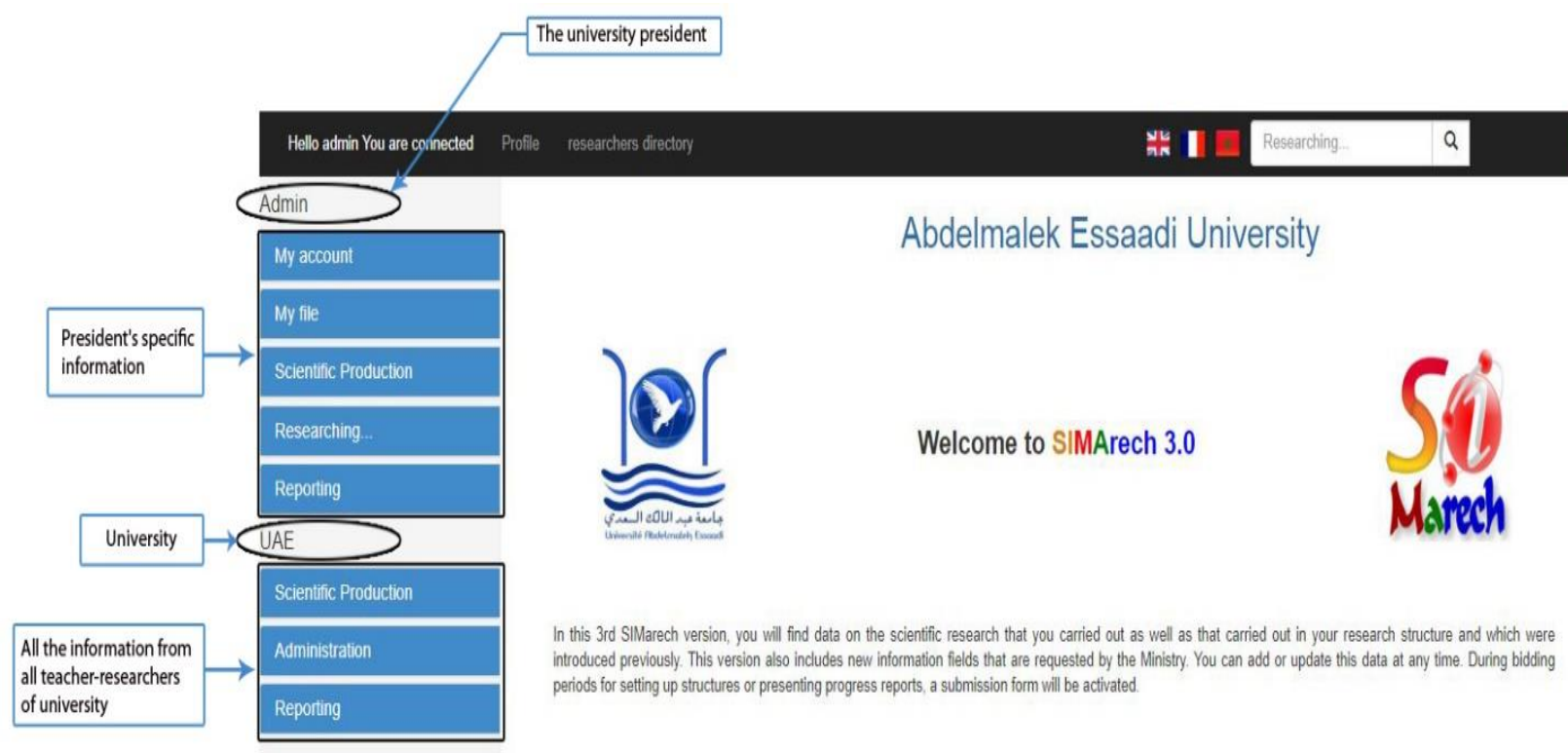

Fig. 2. SIMARECH web application (administrator space) [8]. 


\section{DEVELOPMENT OF THE INTELLIGENT SYSTEM FOR LEARNING HOW TO USE THE MOROCCAN INFORMATION SYSTEM FOR SCIENTIFIC RESEARCH (ISSIMA)}

\section{A. Overview}

E-Learning concerns a method of acquiring knowledge or building knowledge using interactions (actor - actor or actor resource) relayed by a telematics system (electronic, computer connected by networks) [10]. E-learning broadly refers to the use of technologies for learning. This term includes both eeducation, e-learning, e-training, virtual learning, use of ICT; in fact, it is learning using the computer alone or with other multimedia tools [11].

E-learning today nevertheless benefits from international recognition, to find its place among the public. Its effectiveness has been demonstrated several times, sometimes impressively. It represents a reliable alternative to costly face-to-face training and makes it possible to react quickly to the constant evolution of trades [12].

In e-Learning, two levels of complexity can be distinguished for the applications: on the one hand, the systems derived from the computer-assisted instruction (CAI) do not offer any adaptation according to the learner; it is exclusively interested in the data (transmission of the information to be learned). on the other hand those derived from intelligent computer-assisted instruction (ICAI) seeking to understand the learner to provide the best possible response to his or her learning needs [13]-[15]. The ICAI helps to orient learning according to the learner: understand the reasoning of the learner, the reasons for his mistakes, validate and quickly assess his knowledge, his pedagogical preferences to adapt the teaching according to particularities specific to this individual.
To achieve this goal, ICAI has quickly established itself as a highly multidisciplinary field. These latter systems are commonly referred to as Intelligent tutoring system (ITS) [13], [16].

The purpose of ITS is to provide the benefits of individual training. It enables learners to practice their skills by performing tasks in highly interactive learning environments [16], [17]. According to Murray [18], ITSs are computer-based teaching systems that have content in the form of a knowledge base (which specifies what should be taught), teaching strategies (which specify how to teach this content) as well as knowledge about the learner's level of content, in order to dynamically adapt their teaching.

The design of such systems involves specialists in AI, the field taught and the teaching, each of whom has a role to play in the components of the system. In general, ITSs consist of four main models [17]: the domain model, the student model, the tutoring model and the interface.

Fig. 3 shows the different components of a ITS [17], [19].

- The domain model, representing the expert's knowledge of the field;

- The student / learner's model, allowing the state of one's knowledge to be established at a given moment;

- The tutoring or pedagogical model in which the knowledge of one or more pedagogical experts is represented, making it possible to make teaching choices according to the behavior and the model of the student / learner;

- The interface model, allowing the exchange of information between the system and the user.

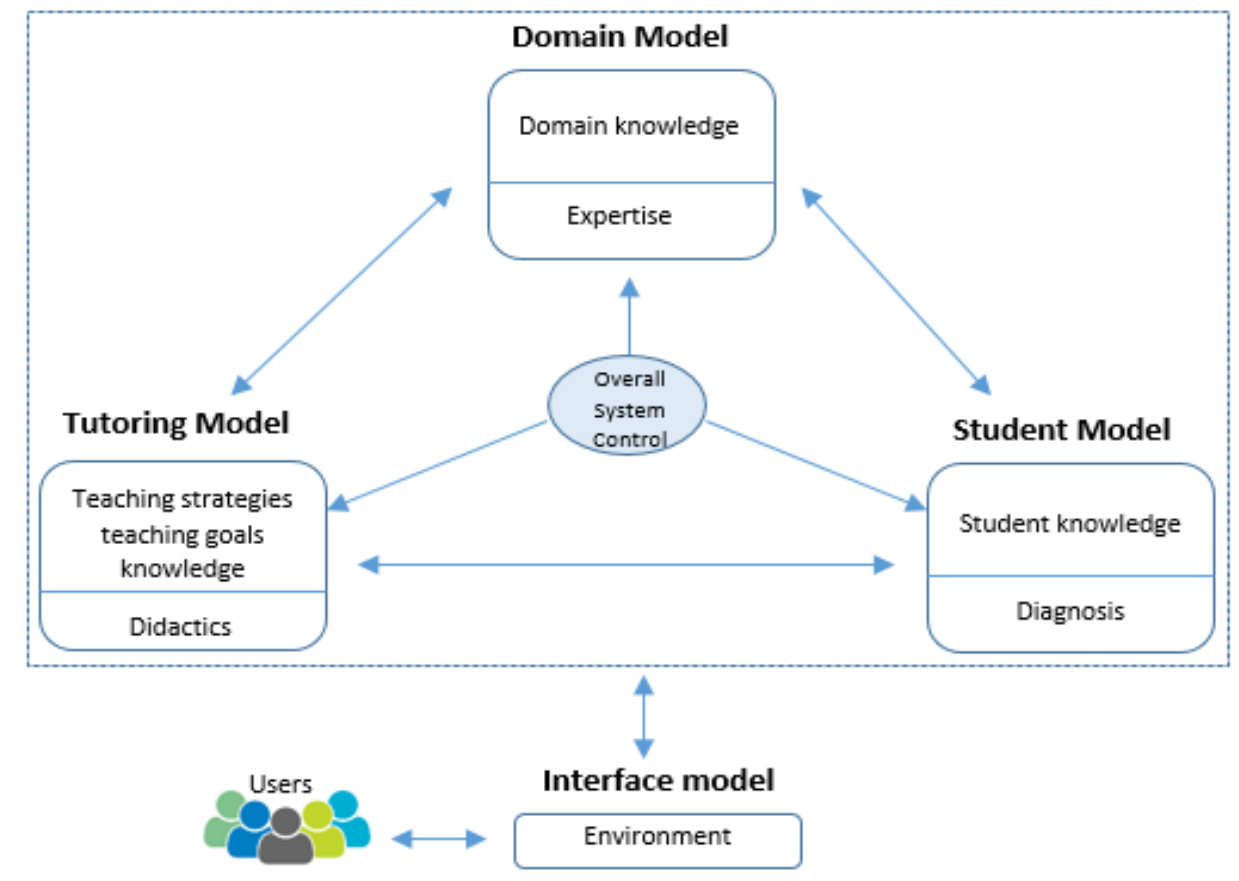

Fig. 3. The components of an intelligent tutoring system [17]. 
ITS includes both a student model and a domain model, both interacting with the tutoring model, which is available to users in the user interface.

There are three main approaches to the development of ITSs [19], [20] :

- The program sequence is made so that the student can easily adapt himself, in addition to the material is demonstrated to the student just when he / she needs it [16].

- ITS gives detailed feedback to the learner about the imperfect or false solution, helping to learn of his mistakes (If the feedback between ITS and the learner is provided, better training results are obtained [21], [22]).

- Problem-solving methods, little help is provided to the learner so that the right solution is reached (if ITS instantly corrects the mistakes made by the learner or shows the correct way to avoid the error, the knowledge of the student becomes deeper and broader [21], [22]).

\section{B. The Objectives of the ISSIMA Training}

In this context, the objectives of the university in this training are to acquire knowledge, skills and Attitudes.

1) Acquisition of knowledge

- Train learners on the principles of SIMARECH.

- Provide learners with the means and knowledge necessary to handle SIMARECH.

- Train learners in operating procedures and management of research units, etc. at SIMARECH.

2) Acquisition of Skills

- Develop learners with the skills they need to perform their tasks.

- Develop skills to improve the usage performance of SIMARECH.

- Provide reminder training when necessary (the case where a skill has not been sufficiently mastered).

3) Acquisition of Attitudes

- Personal effectiveness.

- Allow learners to know each other better at the national level.

- Coach teams / researchers.

Naturally, through these objectives, the training aims at the development of SIMARECH's competence to use, the training also helps to motivate learners to use SIMARECH.

\section{Development of the ISSIMA Intelligent System}

1) The development of the ISSIMA prototype: The development of the intelligent system prototype for learning the use and functionality of SIMARECH, breaks down as follows [23]:
- Design a system architecture based on classical ITS architecture (Fig. 3).

- To elicit raw knowledge expressed by the experts (to identify and bring out the important concepts of the field and the significant relations between these concepts).

- Build a model of learner knowledge and performance representation including diagnostic tools to identify errors and misconceptions and provide mechanisms to help correct them.

- Establish tutorial rules based on tutoring strategies that have been proven effective and are widely used in learning environments [22].

- Implement and evaluate a first stable ISSIMA prototype and offering the basic features.

The long-term goal is to create an intelligent learning system in which it will be possible to access different environments (dependent on connected actor) and to define learning scenarios for the training of the learner. The system will integrate all SIMARECH usage and feature learning scenarios to meet the needs of SIMARECH actors. Its configuration will have to be simple, intuitive and does not require a great competence in computer programming.

2) The operating cycle of ISSIMA: The operating cycle we present here is the one we designed for the ISSIMA system as a whole, i.e. it applies to all the scenarios defined for the training. It is important to note that ISSIMA is designed to be a learning system that can support and offer SIMARECH usage and functionality training (principles, objectives, role, etc.).

It is important to mention that SIMARECH has four types of actors; it is accessible to all teacher-researchers, those who are responsible for structures, deans, and administrative staff at the level of the presidency of the university. Their knowledge, skills or expertise of using the SIMARECH platform differs, so the use of the system does not present the same difficulties for them.

The SIMARECH platform has four spaces. Each actor of SIMARECH has different access from the other. Our ISSIMA system should offer the possibility of integrating different environments and defining adaptive learning scenarios for each SIMARECH actors. Here we describe the overall course of a training session in ISSIMA. The entire training session takes place in the learning environment on which the learner can act, and through which the tutor interacts with the latter.

When the learner enters the ISSIMA system he will be asked to select his profile: trainer or user / learner (for all actors of SIMARECH); then he will have to choose his username from the list of learners of the selected profile and enter his password. If the learner does not have a username, he will be asked to contact the platform administrator. 


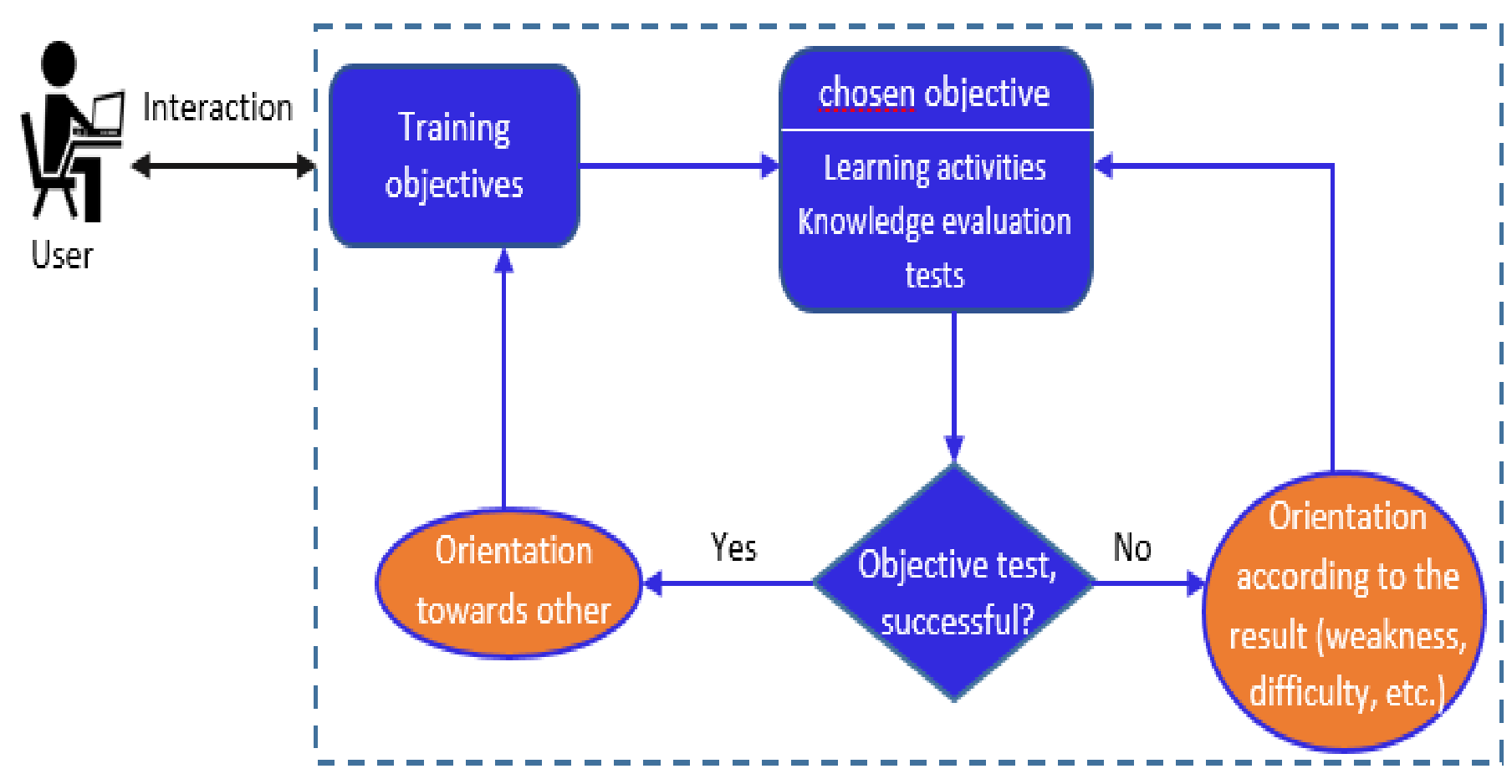

Fig. 4. Course of a training session.

At the very first access to his account, the system will offer him a questionnaire. The answers to the quiz questions will be used to create the psychometric model that will be used to initialize the learner model, allowing the system to establish a first cognitive model that will provide the basic information for the learner's personalized follow-up [24]. After accessing his account, and passing the entrance test, the learner will be asked to choose a scenario (an objective) from those available in the learning environment for which the training was defined. Once the objective is chosen, the learner can begin the training under the supervision of the intelligent tutor who observes his movements in his environment and his behavior, note each of his actions and give him positive or negative feedback.

Each interaction of the learner in his / her learning environment or with the tutor, in case he / she will ask for help for example, will be taken into account by the system and the resulting information will be used to update the learner model as it evolves in training. The tutor asks the expert to determine whether the actions taken by the learner in the training are relevant to the current scenario, and gives feedback to the learner if necessary.

At the end of the training, the model of the learner will be presented to him as well as his degree of reaching the chosen objective that will allow him to see at what level he is compared to other learners having the same user profile (actor) either at his university or at national level. Fig. 4 illustrates in a simplified way the progress of a training session.
3) Technical Implementation Options: In the e-Learning projects, the question of the choice of the platform is essential, Indeed, According to the pedagogical scenario that one wants to use at the level of the architecture, some platforms will be more adapted than of other. As the platform on which our system will be based, we have chosen the Moodle platform that is an extremely powerful tool that we have used to ensure the reliability, efficiency and robustness of our solution. It is the most suitable for our needs, enjoys a good reputation as well as numerous Moodle platform are revealed a great success in the teaching field.

Moodle is the contraction of Modular Object-Oriented Dynamic Learning Environment, is a platform of e-learning of constructivist philosophy, free and open source. In other words, it is an accessible system with a web browser, which allows managing online courses (space for filing documents, online activities with students, registration management and access rights, remote tutoring, etc.), its ergonomic interface and its way of being make it easy to handle and make you want to use it [25].

Moodle is a learning platform designed to provide teachers, administrators, and learners with a single, robust, secure, and integrated system for creating personalized learning environments [26]. Indeed, Moodle gives the possibility to organize courses in the form of the sector; it is also a content management system to which is added educational and communicative interaction tools creating an online learning. 
The application thus makes it possible to create through its network interactions between pedagogues, learners and educational resources [25], [26].

Based on the features of Moodle [25], we will develop a system for learning how to use SIMARECH by using best practices to achieve the educational objectives, functional expectations of the training. This system will be fully automated, will facilitate learning without the intervention of a human tutor and adaptable to the needs and current knowledge of each actor of SIMARECH, which will give this system the main features of the intelligent computer system.

Our automated system will help us increase the effectiveness of training and achieve significant results in terms of learning. This system is open:

- To all actors of SIMARECH, They can access it by their login and password.

- Only trainers (teachers or others) from the University can create one or more objectives on Moodle.

- An administrator who manages the technical part of the system.

\section{CONCLUSION}

We have a strategy to develop an intelligent learning system for the use of Moroccan Information System of Scientific Research (SIMARECH) at national universities, which will be fully automated and adaptable to the needs and current knowledge of each actor of SIMARECH formed in it, which gives this system the main features of the intelligent computer system. This solution will facilitate the use of SIMARECH and reduce administrative costs, save training time, avoid the problem of the availability of SIMARECH users in a specific time.

The system design presented in this article is mainly offered to individual learning situations. The learner's interactions with the learning environment in which he evolves are through a set of actions observable by the system. Throughout the learning process, the learner benefits from the intervention of a machine tutor to guide him in the acquisition of the skills that will enable him / her to complete the training, to be able to understand the functionalities and to use SIMARECH easily.

The development of the SIMARECH intelligent learning system will be a real solution to the difficulties encountered in implementing SIMARECH at the national level.

\section{ACKNOWLEDGMENT}

This work was supported in part by the Ministry of Higher Education, Scientific Research and Management Training to support national projects in the management of scientific research.

\section{REFERENCES}

[1] M. de l'enseignement supérieur de la recherche scientifique et de la formation des Cadres, "Projet de Performance," 2015.

[2] K. Benmoussa, M. Laaziri, S. Khoulji, and M. Kerkeb, "SIMARECH 3: A New Application for the Governance of Scientific Research," First
Int. Conf. Affect. Comput. Mach. Learn. Intell. Syst. Sch., vol. 5, pp. 776-784, 2017.

[3] R. Maroc, “Gouvernance de l'Université Marocaine: Acquis, contraintes et perspectives de développement," 2013. [4] "ENSAT." [Online]. Available:
http://www.ensat.ac.ma/guide/08servicesnumeriquestransversaux.htm.

[5] A. Azirar, A. Belalia, A. Bellamine, A. Ibenrissoul, A. Driouchi, and D. Zejli, "Comment faire du Maroc un hub régional en matière de recherche scientifique et d'innovation ?," 2015.

[6] H. Ameziane, "Projet de developpement 2015-2018," 2015.

[7] J. Gaillard and A.-I. Afifi, "Appui au système national de la recherche (SNR) au Maroc pour une intégration à l'Espace européen de recherche (EER) : jumela....," 2012.

[8] “SIMARech 3." [Online]. Available: http://simarech.uae.ac.ma/.

[9] P. Phobun and J. Vicheanpanya, "Adaptive intelligent tutoring systems for e-learning systems," Procedia - Soc. Behav. Sci., vol. 2, no. 2, pp. 4064-4069, 2010.

[10] E. Kanninen, "Learning styles and e-learning," Master Sci. Thesis, Tampere Univ. Technol., vol. 12, pp. 1-76, 2008.

[11] L. Changlin and W. Kebao, "Integrated e-learning," in 2009 International Conference on E-Business and Information System Security, EBISS 2009, 2009.

[12] J. L. Moore, C. Dickson-Deane, and K. Galyen, "e-Learning, online learning, and distance learning environments: Are they the same?," Internet High. Educ., vol. 14, no. 2, pp. 129-135, 2011.

[13] R. M. Bottino and M. T. Molfino, "From CAI to ICAI: An educational technical evolution," Educ. Comput., vol. 1, no. 4, pp. 229-233, Jan. 1985.

[14] P. Duchastel, S. Doublait, and J. Imbeau, "Instructible ICAI," J. Inf. Technol., vol. 3, no. 3, pp. 162-168, Sep. 1988.

[15] A. Durey and D. Beaufils, “L'ORDINATEUR DANS L'ENSEIGNEMENT DES SCIENCES PHYSIQUES : QUESTIONS DE DIDACTIQUE," 8èmes Journées Inform. Pédagogie des Sci. Phys. Montpellier, 1998.

[16] J. Dāboliņš and J. Grundspeṇkis, "The Role of Feedback in Intelligent Tutoring System,” Appl. Comput. Syst., vol. 14, no. 1, pp. 88-93, 2013.

[17] R. Nkambou, J. Bourdeau, and R. Mizoguchi, Advances in Intelligent Tutoring Systems. 2010.

[18] T. Murray, "Authoring Intelligent Tutoring Systems: An analysis of the state of the art," Int. J. Artif. Intell. Educ., vol. 10, pp. 98-129, 1999.

[19] I. Padayachee, "Intelligent tutoring systems: Architecture and characteristics,” Inf. Syst. Technol., pp. 1-8, 2002.

[20] A. Latham, K. Crockett, D. McLean, and B. Edmonds, "A conversational intelligent tutoring system to automatically predict learning styles," in Computers and Education, 2012, vol. 59, no. 1, pp. 95-109.

[21] F. Gutierrez and J. Atkinson, "Adaptive feedback selection for intelligent tutoring systems," Expert Syst. Appl., vol. 38, no. 5, pp. 6146-6152, 2011.

[22] I. Roll, V. Aleven, B. M. McLaren, and K. R. Koedinger, "Improving students' help-seeking skills using metacognitive feedback in an intelligent tutoring system," Learn. Instr., vol. 21, no. 2, pp. 267-280, 2011.

[23] P. Joel Arthur Karol Djeumo, "Implémentation d'un système tutoriel intelligent de type jeu sérieux pour l'apprentissage des pratiques sécuritaires," 2017.

[24] R. Mislevy, M. Wilson, K. Ercikan, and N. Chudowsky, "Psychometric Principles in Student Assessment," Int. Handb. Educ. Eval., pp. 489531, 2003.

[25] D. R. Tobergte and S. Curtis, Using Moodle, 2nd Edition, vol. 53, no. 9. 2008.

[26] J. Matijašević-Obradović, J. Dragojlović, and S. Babović, "The Importance of Distance Learning and the Use of Moodle Educational Platform in Education," Proc. Int. Sci. Conf. - Sint. 2017, pp. 236-241, 2017. 